\title{
Reflexões sobre educação escolar quilombola
}

\section{Thoughts on Quillombola School Education}

https://doi.org/10.34112/2317-0972a2016v34n68p79-91

\author{
Max Silva da Rocha ${ }^{1}$ \\ José BEzERRA DA SILva²
}

RESUMO: Este artigo comenta a incipiente Educação Escolar Quilombola, reflete sobre suas características e os seus beneficiados. Evidencia também a ingerência do Banco Mundial nesse modelo de educação, cujo projeto se direciona aos países periféricos, pois visa fortalecer basicamente o Ensino Fundamental, priorizando os atos de ler, escrever e contar. Dessa forma, esse projeto de educação escolar se fundamenta na lógica do capital, substituindo o confronto de classes por formas sociais conciliatórias, capazes de reforçar a sociabilidade consensual apregoada pelo neoliberalismo, em que se destacam como bandeira de luta somente a obtenção da cidadania e a participação democrática, mas sem romper com o sistema. Ver-se-á também ser possível ao professor/a de aluno quilombola ressignificar as elaborações sobre a Educação Escolar Quilombola, fazendo que esse modelo de educação contribua no processo de lutas e de melhorias locais, sem perder de vista a possibilidade de visualizar uma sociedade plenamente emancipada.

Palavras-chave: Educação quilombola; Banco Mundial; neoliberalismo.

ABSTRACT: This article comments on the incipient Quilombola School Education, reflecting on its characteristics and beneficiaries. It also highlights the interference of the World

1. Universidade Estadual de Alagoas, Palmeira dos Índios, AL, Brasil.

2. Faculdade São Tomás de Aquino, Palmeira dos Índios, AL, Brasil. 
Bank in this education model, designed to be directed to the peripheral countries, aiming primarily to strengthen basic education, giving priority to reading, writing and counting. Thus, this education project is based on the logic of capital, replacing the class struggle by conciliatory social which strengthen the consensus within neoliberalism, defending ideas of citizenship and democratic participation, but without changing the system. It is possible for the teacher of a quilombola student to reframe the ideas of Quilombola School Education, making this education model a means of contribution for the process of struggles and local improvements, without losing sight of the possibility of a fully emancipated society. KEYWORDS: Quilombola education; World Bank; neoliberalism.

\section{INTRODUÇÃO}

O capitalismo mercantil, cujo epicentro foi a Europa, foi impulsionado, inicialmente, pelas invasões de novas terras, pelo desenvolvimento do comércio e pela escravidão negra, que se tornou de grande importância, por atender às exigências colonizadoras das terras recém-invadidas, como no caso do Brasil. Consequentemente, a sociabilidade capitalista mercantil despersonalizou o negro, a ponto de tê-lo como simples mercadoria - forçado a trabalhar até a morte, destituído de todos os possíveis direitos, dentre os quais o de frequentar a escola. Essa proibição se estendeu para depois do sistema colonial, pois alcançou o Império e durante a República foi cultivada disfarçadamente. Basta ver a Reforma Couto Ferraz (Decreto n ${ }^{\circ}$ 1.331-A, de 17 de fevereiro de 1854), cujo artigo 69 estatui:

Não serão admitidos à matrícula, nem poderão frequentar as escolas:

$1^{\circ}$. Os meninos que padecem moléstias contagiosas.

$2^{\circ}$. Os que não tiverem sido vacinados.

$3^{\circ}$. Os escravos.

Se não bastassem "os escravos", por meio de sutilezas e ardis, a citada reforma se insurgiu contra os alforriados, que poderiam padecer de "moléstias contagiosas" ou não ter, por qualquer modo, sido "vacinados". Com essa lei, os brancos e os filhos de brancos podiam frequentar os bancos escolares sem incorrer em riscos de contaminação. Seguindo o mesmo rumo, no artigo $6^{\circ}$, a Constituição Federal de 1824 também proibiu o acesso do escravo à escola. Com a República, a situação parece ter sido mais agravada, pois, dadas as modificações no cenário político-econômico 
e social do País, a população afro foi parcialmente substituída pelos imigrantes, perdendo, desse modo, os espaços de trabalho que há séculos ocupara como escravizados. Quanto às comunidades negras rurais, permaneceram em total esquecimento e isolamento, só adquirindo visibilidade durante o processo constituinte que resultou na elaboração da Constituição Federal, em 1988. Atualmente, em atendimento às modificações implantadas no cenário neoliberal internacional e com a escolha feita por diversos organismos internacionais, especialmente o Banco Mundial, da educação como forma de reduzir a pobreza, o nosso país intensificou a prestação do ensino fundamental àqueles até então fora da escola - grosso modo, à população afro-brasileira.

A presença de organismos internacionais manipulando o sistema educacional nacional é histórica. Atualmente esse sistema vem sendo assistido pelo Banco Mundial. Na obra Marxismo, educação e lutas de classes, organizada por Jimenez e outros, publicada em 2010, vemos a avalanche de intromissão dos mais diversos organismos internacionais em conluio com o empresariado nacional para enquadrar a educação escolar nacional na tutela neoliberal. Nesse âmbito, o Banco Mundial, além de financiar o processo educativo, dita normas de comportamento, financia projetos e pesquisas, disponibiliza técnicos e especialistas e condiciona os financiamentos à abertura do mercado interno ao capital internacional.

Dessa forma, o nosso ensino fundamental, cujo tempo de duração coincide com as proposições do Banco Mundial para a educação básica, se presta a tornar os pobres em trabalhadores produtivos e em cidadãos consumidores, bem como a introjetar a política do consenso, com vistas a persuadir a população dos países periféricos a se conformar com o status quo, impondo o sistema capitalista como a última e única forma de sociabilidade possível.

Assim, a Educação Escolar Quilombola, apesar da sua imensa importância, pois se prontifica a atender comunidades historicamente desassistidas, padece desse grande problema que é a interferência do Banco Mundial na sua moldura e feitio, ocasionando a intensificação de um modelo social essencialmente opressor, que é o capitalismo.

Neste artigo, subdividido em dois tópicos, será analisada a formação da Educação Escolar Quilombola pelo Estado brasileiro, bem como a sua vinculação às políticas neoliberais, sob a regência do Banco Mundial, e ainda a possibilidade de ser tomada como força motriz capaz de trazer à tona fatores alienantes, não poucas vezes disfarçados em políticas reparadoras. No entanto, dado o caráter de classe da sociedade brasileira, os professores e as professoras de alunos quilombolas podem, 
ao utilizar os conteúdos da Educação Escolar Quilombola, desencadear atividades educativas revolucionárias, sem perder de vista a imensa contribuição que podem dar à organização dessas comunidades e às suas lutas por direitos.

\section{EdUCAÇÃo ESCOLAR PARA QUILOMBOLAS}

As populações quilombolas nacionais têm sido alvo de grande diversidade de políticas protecionistas estatais, a contar da III Conferência Mundial de Combate ao Racismo, à Discriminação Racial, à Xenofobia e Intolerância Correlata, ocorrida em Durban, África do Sul, em 2001. No bojo dessas políticas tomou vulto a Educação Escolar Quilombola, cuja elaboração está sendo discutida pelo Ministério da Educação (MEC) via Secretaria de Educação Continuada, Alfabetização, Diversidade e Inclusão (Secadi). Esse modelo diferenciado de educação escolar se centraliza na realidade das comunidades quilombolas, valoriza a territorialidade como espaço educativo, estabelece contatos respeitosos com valores ancestrais cultuados pela comunidade: a oralidade; a religião de matriz africana e demais questões vinculadas à população afro-brasileira; o combate ao racismo, às desigualdades raciais, que, segundo a Organização das Nações Unidas - ONU -, são as principais fontes geradoras das desigualdades sociais.

A elaboração de uma proposta de educação escolar quilombola não significa romper com os conhecimentos escolares, mas sim, buscar incorporar a esses conhecimentos a dinâmica do cotidiano, o jogo simbólico da vida, o crescimento e aprimoramento que permeiam as comunidades quilombolas marcados na dimensão do desafio, da luta e do enfrentamento das dificuldades que se materializam em distintos graus nessas comunidades. Assim, o lugar deve ser considerado um componente indispensável para construção da educação escolar quilombola. Os conteúdos escolares ao sintonizarem a natureza histórica e cultural das comunidades quilombolas terão sentido e relevância para os alunos/as quilombolas. $O$ vínculo da escola com a concretude vivenciada é talvez a mais importante estratégia político/pedagógica para ajudar esses alunos/as a compreender e indagar sobre suas realidades para poder modificá-las. (PARANÁ, 2010, p. 12).

Semelhantemente, o Centro de Cultura Luiz Freire (CCLF), sediado no Recife e protagonista de excelente trabalho com os quilombolas dos estados de Pernambuco, Paraíba e Ceará, descreve a Educação Escolar Quilombola com um processo que 
vincula a família à convivência comunitária, sendo, de qualquer modo, um recorte da sistemática educacional nacional, dinamizado desde 2008, com os preparativos para a elaboração do Plano Nacional de Educação - PNE 2011-2020, cuja efetividade se deu entre os dias 28 de março e $10^{\circ}$ de abril de 2010, com a Conferência Nacional de Educação - CONAE. O CCLF (s. d., p. 7) enfatiza que

[a] educação quilombola é compreendida como um processo amplo - que inclui a família, a convivência com os outros, as relações de trabalho e com o sagrado e as vivências da comunidade. Assim, compreende-se a educação como um processo que faz parte da humanidade e está presente em toda e qualquer sociedade, e a escolarização é um recorte do processo educativo mais amplo.

O modelo de educação para os quilombolas se fortaleceu com a realização do Primeiro Seminário Nacional de Educação Escolar Quilombola, ocorrido em Brasília, em novembro de 2010, que contou com a participação de 240 pessoas, entre as quais pesquisadores, professores e lideranças quilombolas. Posteriormente foram realizadas três audiências públicas, a primeira no Maranhão, a segunda na Bahia e a terceira em Brasília, a fim de consolidar a discussão em torno dos conteúdos do Plano Nacional de Educação Quilombola, bem como de suas diretrizes.

O relatório do Primeiro Seminário de Educação Quilombola definiu várias propostas norteadoras da referida educação, as quais se vinculam às proposições do Banco Mundial para a educação dos países periféricos. Segundo nosso olhar, as propostas são as seguintes:

- garantia de acesso, permanência e conclusão da educação básica;

- fornecimento de material didático diferenciado para o ensino fundamental;

- avaliação tipo emancipatória, processual, diagnóstica e formativa da aprendizagem;

- educação como meio de reduzir a pobreza e preparar mão de obra para o mercado;

- qualificação dos pobres para torná-los produtivos;

- centralidade no ensino fundamental (educação básica);

- participação da comunidade beneficiada na discussão dos programas e projetos;

- capacitação de professores do ensino fundamental que atuam nas comunidades remanescentes de quilombos;

- ampliação da rede física das escolas quilombolas. 
Acrescentem-se a esse modelo educacional os termos do artigo 26-A da Lei ${ }^{\circ}$ 9394/96 (Lei de Diretrizes e Bases da Educação Nacional - LDBEN) (BRASIL, 1996), que determina se ensinem, nas escolas de todo o País, a história da África e dos africanos, a cultura afro-brasileira e indígena e as lutas da população negra e indígena. Também a Declaração de Educação para todos, realizada em Jomtien, Tailândia, em 1990, coordenada pelas Nações Unidas - ONU - e com a participação efetiva do Banco Mundial, exerceu forte influência na composição desse modelo.

Passado mais de um século da abolição, o Estado brasileiro voltou-se à população afro e tem buscado atendê-la com um conjunto de políticas públicas, entre as quais está a educação escolar. Esse modus operandi estatal se enquadra no bojo de uma política global oriunda do Banco Mundial para os países periféricos. Desse modo, e a fim de explicitar mais adequadamente a afirmação anterior, nós nos reportamos aos anos setenta do século XX, ocasião em que o Banco Mundial já demonstrava interesse pelo campo educacional, porque já era ideia prevalecente ser a educação o instrumento útil e necessário para reduzir a pobreza, sobretudo dos $40 \%$ mais pobres do globo. Naquela época, McNamara, presidente do referido Banco, se expressou do seguinte modo:

Quando os privilegiados são poucos, e os desesperadamente pobres são muitos e quando a diferença entre ambos os grupos se aprofunda em vez de diminuir, só é questão de tempo até que seja preciso escolher entre os custos políticos de uma reforma e os riscos políticos de uma rebelião. Por este motivo, a aplicação de políticas especificamente encaminhadas para reduzir a miséria dos $40 \%$ mais pobres da população dos países em desenvolvimento, é aconselhável não somente como questão de princípio, mas também de prudência. A justiça social não é simplesmente uma obrigação moral, é também um imperativo político [...]. Mostrar indiferença ante a frustração social equivale a fomentar seu crescimento. (McNAMARA apud PEREIRA, 2010, p. 203).

Percucientemente, o Banco fez convergirem para um único âmbito o racismo e a discriminação racial, a pobreza e a educação. Grosso modo, esses $40 \%$ mais pobres são afrodescendentes (no Brasil esse número é bem maior) ${ }^{3} \mathrm{e}$, como justiça social, há apenas o recurso de reduzir a miséria desses $40 \%$ para evitar possíveis rebeliões que venham a incomodar os poucos privilegiados. Assim, o Banco assume o grandioso

3. Mário Theodoro (Org.) publicou, pelo Instituto de Pesquisa Econômica Aplicada (IPEA), uma série de artigos com o título: As políticas públicas e a desigualdade racial no Brasil: 120 anos após a abolição, que indicam o tamanho da desigualdade social do Brasil. Vejam-se também os dados do censo de 2010, fornecidos pelo IBGE. 
papel de fomentar a educação básica, isto é, de ensinar a ler, escrever e contar, para, em atendimento ao modelo neoliberal, implementar a política do consenso. O Brasil tem se assujeitado a essa política globalizante, pois o citado Banco tem investido na maioria dos projetos educacionais brasileiros, cujos percentuais "eram apenas de $2 \%$ nos anos 87-9o e alcançaram a cifra de 29\% nos anos 91-94" (TOMMASI; WARDE; HADDAD, 1996, p. 196).

A diretiva internacional da educação pelo Banco Mundial engloba as populações afrodescendentes. Por isso coordenou, juntamente com a Organização das Nações Unidas, a III Conferência Mundial de Durban, e aumentou consideravelmente a linha de investimento direcionada para a educação básica. Quanto ao ensino superior, o Banco Mundial propõe que seja assumido pelo próprio estudante, pois, segundo o Banco, no caso brasileiro, têm sido privilegiados aqueles que podem pagar. Por isso, o Banco incentiva a privatização do ensino superior.

O nosso país tem se adequado positivamente às exigências do Banco, não somente quanto ao desempenho no combate à pobreza através de programas sociais (Bolsa família), mas também com a normatização da educação de acordo com os interesses deste. Tais fatos são importantes e decisivos para alavancar o potencial do Brasil, elevando-o a patamares de ótimo captador de recursos.

O número de projetos aprovados no período demonstra uma atuação constante e um relacionamento consolidado entre os governos brasileiros (federal, estadual ou municipal) e o Banco Mundial. Ainda que uma comparação dos dois primeiros anos do governo FHC (primeiro mandato) com o primeiro ano do governo Lula possa fazer parecer que houve uma certa precaução dos novos dirigentes do país quanto à realização de acordos com o Banco, no início dos seus mandatos, em virtude do número de projetos aprovados, um olhar voltado ao terceiro ano do governo $\mathrm{FHC}$ revela que o número de acordos assinados cresceu em mais de $100 \%$ em relação aos anos anteriores e o mesmo ocorre em relação ao segundo ano do governo Lula, em que o número de projetos cresce mais de 30\%. (MACHADO, 199?, p. 2).

Os investimentos do Banco na educação atrelam o País ao comércio sem barreiras, pintam as relações sociais com características da livre concorrência e favorecem o mercado interno de conhecimento, por meio do qual os empresários passam a atuar mais intensamente na negociação do saber. E o Estado nacional, através dos seus governos, tem flexibilizado a legislação para melhor atender a esse desiderato. 
Essa forma neoliberal do capital prima pelas relações mercadológicas e torna a educação uma valiosa mercadoria. Se não bastasse isso, os investimentos demandam grande diversidade de contratos comerciais, por meio dos quais se estabelece profunda desigualdade entre países centrais e países periféricos.

Embora o Bird ${ }^{4}$ empreste apenas para o setor público, o mundo dos negócios tem entrada direta no funcionamento das suas operações. Isso ocorre porque o financiamento concedido pelo Bird anualmente gera em torno de 40 mil contratos que envolvem um grande volume de compra e venda de bens e serviços de todo o tipo, parte dos quais por meio de licitações internacionais abertas a empresas sediadas nos Estados-membros. Historicamente, as empresas estabelecidas nos países capitalistas mais industrializados abocanham a maioria esmagadora dos contratos, graças a lobbies bem organizados e silenciosos, dos quais fazem parte os seus respectivos governos. (PEREIRA, 2010, p. 46).

Assim, a educação escolar foi priorizada pelo Banco, que, além de subsidiá-la, passou também a sugerir seus conteúdos. Neste âmbito, o Brasil vem captando elevadas somas para equalizar a educação nacional às diretivas internacionais, bem como para atender às exigências do mercado globalizado, para o qual a educação é apenas mais uma mercadoria. Nessa perspectiva, a educação escolar e a educação escolar quilombola se vinculam ao modelo social neoliberal atualmente em voga, que propaga ser a cidadania, ao lado da democracia, a mais alta forma de sociabilidade que a humanidade pode almejar, necessitando apenas ser continuamente aprimorada, lapidada aqui e ali, para, enfim, ir aos poucos se tornando melhor.

Não se pode negar, porém, a grande importância da Educação Escolar Quilombola no cenário nacional, como também a imensa importância da participação cidadã na atual sociedade democrática. São conquistas preciosas para a humanidade em geral e para os afro-brasileiros em particular. No entanto, essas grandiosas conquistas são, por si sós, incapazes de eliminar as desigualdades sociais, as quais se originam das manifestações da propriedade privada, do Estado e do capital. Desse modo, por mais que se valorize a Educação Escolar Quilombola - que já é portadora, per se, de profundas limitações, pois se estende apenas ao ensino fundamental - e que se valorizem também a cidadania e a democracia, as desigualdades sociais persistirão, justamente porque nem a educação, nem a cidadania e

4. Banco Internacional para Reconstrução e Desenvolvimento. 
nem a democracia romperão com a lógica da compra e da venda da força de trabalho, maneira eficiente de manter a posse do capital em poucas mãos e de tornar a maioria populacional alienada e destituída das condições básicas de sobrevivência.

\section{EDUCAÇÃO ESCOLAR QUILOMBOLA NA CONTRAMÃO DAS LUTAS QUILOMBOLAS}

O Estado brasileiro, a contar da Constituição Federal de 1988, tem concedido às populações quilombolas diversos direitos - desde a definição de seu território, à moradia, saúde, alimentação através da cesta quilombola e de vários outros benefícios emanados de projetos emanados do governo federal. Por isso, a fim de alcançar esses direitos básicos, os quilombolas têm despendido grandes esforços, e os resultados obtidos são ínfimos. Nas nossas viagens de visita às comunidades quilombolas alagoanas nos deparamos com situações de absoluta miséria: casas de taipa sem sanitário, acesso à terra limitadíssimo, muitos aquilombados residindo em casas de lona, dificuldades enormes para encontrar água potável e muitos outros problemas graves. Há comunidades afetadas por doenças de pele, nanismo e cegueira. Diante desse quadro estarrecedor, a Educação Escolar Quilombola que vem sendo divulgada ou passa ao longe ou simplesmente maquia a realidade, focando seu discurso em outros aspectos, como, por exemplo, no alavancamento da cultura local, nas suas festas e comemorações, querendo, de certo modo, enrijecer a existência como está posta e conduzindo as crianças e os jovens a conservar na sua cotidianidade a estrutura de miserabilidade como se fosse algo natural, com a qual se deve conviver pacificamente.

Mostradas essas situações de imensas carências, três fatores se tornam evidentes: primeiro - o Estado inegavelmente não acabará com a pobreza em geral, nem com a pobreza dos quilombolas. É essencialmente o propulsor dessa situação. Segundo - nem a educação e, menos ainda, a Educação Escolar Quilombola darão cobro a essas carências, pois a causa das desigualdades sociais deve ser buscada nas relações de compra e venda da força de trabalho, e não nas produções culturais, educacionais, artísticas e assemelhadas. Terceiro - a situação dos quilombolas resvala para o problema de classe social; sem negar, porém, a constante presença de racismo e de discriminação na nossa sociedade.

Sendo desse modo as coisas, a Educação Escolar Quilombola necessariamente teria que tomar outros rumos e jamais aqueles engendrados pelo Banco Mundial e correntemente aceitos pelo Estado brasileiro. Assumiria, portanto, a postura de 
classe e somente desse modo responderia adequadamente às lutas travadas pelos quilombolas, levando-os a entender que os seus problemas estão vinculados às movimentações do capital e toda solução forjada pelo Estado não passará de solução paliativa. Noutras palavras, não se dará real transformação social, mas ocorrerão apenas algumas mudanças.

Deduz-se, logicamente, da afirmação anterior, que a educação e, particularmente, a educação afro-quilombola tanto podem se manter como sustentáculo do sistema capitalista, como podem se transformar na mediação para a construção de uma sociedade plenamente emancipada, pois, admitindo o dilema de classes, aspecto constitutivo essencial da sociedade brasileira, a educação se verá forçada a se efetivar dentro desse dilema.

Sendo a escola uma instituição historicamente determinada, como uma construção humana que se articula ao processo de produção das condições materiais de sua existência, como uma dimensão da realidade humana, para além da mera reprodução da sociedade burguesa, pode a educação articular-se plenamente na construção da sociedade sem classes. [...] Neste sentido, o educador precisa romper com as pedagogias escolares articuladoras dos interesses da burguesia e vincular sua concepção e sua prática a uma perspectiva revolucionária de homem e de mundo. Não se trata simplesmente de aderir a uma concepção científica de mundo e seu poder desvelador da realidade, mas de assumir, na teoria e na prática, isto é, na práxis, uma concepção transformadora da vida, do homem e do mundo. (LOMBARDI, 2005, p. 33-34).

Desse modo, para ser possível uma Educação Escolar Quilombola comprometida com as lutas quilombolas e que, ao mesmo tempo, indique outras saídas para além da dimensão de direitos, necessariamente as atividades educativas deverão ter por base uma postura revolucionária, romper com os interesses burgueses e impor-se como práxis transformadora do mundo dos homens. Esse modus operandi de atividades educativas, enquanto mediação para uma sociabilidade plenamente emancipada, se efetiva nos seguintes requisitos elencados por Tonet (2005, p. $232 \mathrm{e}$ seguintes). Primeiro - domínio amplo e aprofundado a respeito do fim que se quer atingir; segundo - apropriação do conhecimento a respeito do processo histórico real, em suas dimensões universais e particulares; terceiro - conhecimento da natureza essencial do campo específico da educação; quarto - domínio dos conteúdos específicos, próprios de cada área do saber, sejam eles integrantes das ciências da 
natureza, das Ciências Sociais ou da Filosofia; e quinto - proceder à articulação da atividade educativa com as lutas desenvolvidas pelas classes subalternas, especialmente com as lutas daqueles que ocupam posições decisivas na estrutura produtiva.

Sabe-se da impossibilidade de se desenvolver uma educação revolucionária, sobretudo quando o Estado é o seu gestor. Mas ficam brechas para a realização de atividades educativas revolucionárias, as quais podem, num primeiro momento, primar pelos direitos, pela cidadania fundada na democracia participativa. No entanto, direitos sociais e cidadania participativa, apesar de muito importantes, são limitados, porque conservam os princípios norteadores da sociabilidade neoliberal. Dar caráter revolucionário às atividades educativas é a única maneira possível de humanizar o homem, historicamente desumanizado pelo capital.

\section{CONSIDERAÇões Finais}

A importância da educação escolar nas sociedades contemporâneas é inequívoca. Manter populações inteiras desescolarizadas é a política da perpetração da miséria. Entretanto, propagar a escolarização como meio transformador da sociedade pode consistir tanto em equívoco como em maldade. Equívoco porque a educação se constitui em instrumental de mediação para a manutenção do status quo ou para a sua transformação, pois "a educação é uma das atividades que atuam sobre a subjetividade, visando a influenciar os indivíduos a agirem de formas determinadas" (MACENO, 2011, p. 38-39). Desse modo, as ações decorrentes do processo educativo influenciarão os indivíduos para a conservação da sociabilidade posta ou para a sua radical transformação. Ela (a educação) atua como força colaborativa da transformação somente quando os indivíduos são identificados em classes. "As identidades de classe possuem uma conexão estreita que possibilitam passar de um estado para outro através do movimento das contradições" (BOGO, 2010, p. 9). Há maldade quando se inflama nas consciências a concepção de que a educação funciona como mera mercadoria e não como um bem da humanidade que deve ser transmitido às novas gerações. Enquanto mercadoria se submete aos interesses empresariais, descambando para um processo de surda domesticação. $O$ indivíduo pode saber ler, escrever e contar e simplesmente integrar o rebanho de domesticados.

A discussão alinhavada neste artigo se volta à problemática da classe social, presente na nossa sociedade e especialmente entre os quilombolas. Com isso não negamos, sob nenhuma hipótese, a presença de racismo e de discriminação na 
sociedade brasileira e alagoana. Apenas se quer chamar atenção para o fato de que combater o racismo e a discriminação, sem combater o capital, a propriedade privada, o Estado, seria apenas trocar seis por meia dúzia ou prender alguém com algemas de ouro e dizer que não está preso, porque a exploração permanece e em condições de se renovar indefinidamente.

É característica da Educação Escolar Quilombola a discussão em torno da demarcação do território quilombola enquanto espaço educativo. Sabemos, porém, que pouquíssimas comunidades têm seu território demarcado, e os ruralistas têm se movimentado no sentido de impedir as demarcações. O Estado, por sua vez, se utiliza de grande morosidade para viabilizar esse direito. Por outro lado, o agronegócio cresce assustadoramente e com o beneplácito financeiro do governo federal.

Diante de tudo isso, parecem caber aos professores(as) duas alternativas: uma apropriar-se da Educação Escolar Quilombola para desenvolver atividades educativas, levando em consideração a realidade concreta dos quilombolas, sem perder de vista a questão da classe social; outra - manter-se enrodilhados nas discussões que focam o racismo e a discriminação como únicos males sociais, sem apontar perspectivas de superação do capital, conservando-se em diálogo cordial com o Estado e seus agentes.

Atividades educativas revolucionárias apontam para uma sociabilidade forjada no trabalho livre e associado.

\section{REFERÊNCIAS}

BOGO, Ademar. Identidade e luta de classe. São Paulo: Expressão Popular, 2010.

CENTRO DE CULTURA LUIZ FREIRE (CCLF) e INSTITUTO SUMAÚMA. Educação quilombola: um direito a ser efetivado. Recife, s.d. Disponível em: <http://www.dhnet.org.br/ dados/cartilhas/dht/cartilha_cclf_educ_quilombola_direito_a_ser_efetivado.pdf $>$. Acesso em: 13 maio. 2016.

LOMBARDI, José Claudinei. Educação, ensino e formação profissional em Marx e Engels. In: ; SAVIANI, Dermeval (Org.). Marxismo e educação: debates contemporâneos.

Campinas: Autores Associados, 2005. p. 01-38.

MACENO, Talvanes Eugênio. Educação e universalização no capitalismo. São Paulo: Baraúna, 2011.

MACHADO, Célia Tanajura. Atuação do Banco Mundial em educação no Brasil entre 1993 e 2004. Disponível em: <http://www.anped.org.br/reunioes/28/textos/gto5/GTo5/121>. Acesso em: 13 maio 2011.

PARANÁ. Secretaria de Estado da Educação. Educação escolar quilombola: pilões, peneiras e conhecimento escolar. Curitiba, Paraná: Secretaria de Educação e Desporto, 2010. 
PEREIRA, João Márcio Mendes. O Banco Mundial como ator político, intelectual e financeiro - 19442008. Rio de Janeiro: Civilização Brasileira, 2010.

SEMINÁRIO NACIONAL DE EDUCAÇÃO QUILOMBOLA, 1., 2010, Brasília: MEC. Disponível em <http://educacaoquilombola.mec.gove.br/>. Acesso em: 12 mar. 2011.

TOMMASI, Livia de; WARDE, Miriam; HADDAD, Sérgio. (Org.). O Banco Mundial e as políticas educacionais. São Paulo: Cortez, 1996.

TONET, Ivo. Educação, cidadania e emancipação humana. Ijuí: EDUNIJUÍ, 2005.

\section{SOBRe OS AUTORES}

Max Silva da Rocha é graduando do Curso de Letras - Português e suas literaturas (Universidade Estadual de Alagoas) e faz também Especialização em Linguística Aplicada na Educação (Universidade Candido Mendes e Instituto Prominas). É bolsista do Programa Institucional de Bolsa de Iniciação à Docência - PIBID/ CAPES/UNEAL, integrante do grupo de pesquisa Linguagem e Retórica (CNPq), liderado pela Professora Doutora Maria Francisca Oliveira Santos (UFAL/UNEAL).

E-mail:msrletras@gmail.com

José Bezerra da Silva é graduado em Direito (Centro de Estudos Superiores de Maceió) e em Filosofia (Faculdade Santo Tomás de Aquino). Tem Especialização em Educação Ambiental (Universidade Federal de Alagoas e Instituto Lagoa Viva) e Mestrado em Educação (Universidade Federal de Alagoas). Atualmente é professor do Curso de Filosofia da Faculdade Santo Tomás de Aquino e integra o Grupo de Pesquisa Trabalho, Educação e Ontologia Marxiana. Pesquisa Educação Escolar Quilombola e o ensino de Filosofia no nível médio.

E-mail: jbcartorio@ibest.com.br

Recebido em o1 de junho de 2016 e aprovado em 15 de dezembro de 2016. 